\title{
THE GLOBAL SUSTAINABILITY INDEX: AN INSTRUMENT FOR ASSESSING THE PROGRESS TOWARDS THE SUSTAINABLE ORGANIZATION
}

\author{
GRECU Valentin \\ assistant professor, Ph.D., Faculty of Engineering / Department of Industrial Engineering and Management, \\ "Lucian Blaga" University of Sibiu, Sibiu, Romania, valentin.grecu@ulbsibiu.ro
}

\begin{abstract}
There is rarely an optimal solution in sustainable development but most frequently a need to build compromises between conflicting aspects such as economic, social and environmental ones and different expectations of stakeholders. Moreover, information is rarely available and precise. This paper will focus on how to use indicators to monitor sustainable development, integrating the information provided by many of them into a complex general sustainability index. Having this general indicator is essential for decision makers as it is very complicated to evaluate the performance of the organization based on multiple indicators. The objective of this paper is to find mathematical algorithms for simplifying the decision-making process by offering an instrument for the evaluation of the sustainability progress.
\end{abstract}

Key words: Sustainable Organization; Decision Support System; Global Sustainability Index

\section{Introduction}

Sustainable Development (SD) within an Organization can be achieved by Corporate Social Responsibility (CSR) [1]. CSR aims to find an equilibrium between economic, social and environmental considerations. With all these considerations, the management of the Organization is becoming more and more complex due to the increasing number of: (i) regulations to fulfil, (ii) other actors that are impacted by the decisions of the Organization who must be consulted and (iii) indicators (parameters or criteria) to follow.

Corporate sustainability is not just a buzzword —-for many industry leaders and corporations, it has become an invaluable tool for exploring ways to reduce costs, manage risks, create new products, and drive fundamental internal changes in culture and structure. However, integrating sustainability thinking and practice into organizational structure is not a trivial task and it requires a vision, commitment and leadership. It also requires a systems approach with an appropriate management framework that enables design, management and communication of corporate sustainability policies [19].

As it has been commonly stated in classical economic and management theories, firms need to make profits in order to survive. However, management needs to adopt a viable posture in the face of a variable environment. This new vision promoted by the SD principle has changed the way profit, costs and risks are considered. Indeed, profit is not only financial quantification (e.g. euro), but also represents social and environmental gains (e.g. more diversity within the organization and less pollution). The SD principle needs a strong political engagement because of the constant need to seek equilibrium between economic, environmental and social concerns that cannot be obtained without the implementation of a participative governance model.

This paper will focus on how to use indicators to monitor sustainable development, integrating the information provided by many of them into a complex general sustainability index. Having this general indicator is essential for decision makers as it is very complicated to evaluate the performance of the organization based on multiple indicators. The objective of this paper is to find mathematical algorithms for simplifying the decision-making process by offering an instrument for the evaluation of the sustainability progress.

To move from an ethical perspective of operation to an action, the SD principle requires methods and tools to be implemented. Multi-criteria decision aid methodology can help practitioners to deal with the expectations and perceptions of different actors with varied objectives to fulfil (economic, social and environmental).

The integrative general sustainability index is based on mathematic algorithms and aggregation procedures that have been developed [2] or adapted. 


\section{Different levels of decision with the Sustainable Organization}

Different actions can be taken at different levels of decision-making within the Organization. Merad et al [1] suggest that these levels are differentiated according to: (i) the practical objectives that are sought, (ii) the nature and the level of information/knowledge that is available and (iii) the potential impacts:

- $\quad$ Strategic. At this level, action planning is the objective of decision-making. The decision is a long term one (over 8 years) and is dominated by both political and regulatory dimensions. The information is abundant but imprecise and difficult to sort and select at this level.

- $\quad$ Tactical. At this level, the decisions are less influenced by political and regulatory dimensions. The decision is a middle term decision (4 years). The decisions are under the constraints and objectives within the Organization (social, technical and economic).

- $\quad$ Operational. At this level, decision-making refers to short-term goals achieved in less than 1 year. The decisions made are more concrete involving technical information which is often specialized, precise, and more specific than the higher levels.

For each level of decision, the SD principle makes the decision maker reach for an equilibrium between economic, social and environmental concerns (risks/costs, benefits) [1]. The difficulty here is to both (i) clarify what measures (actions) must be taken at each level of decision-making and (ii) consolidate all the measures at each level in order to become a Sustainable Organization (SO).

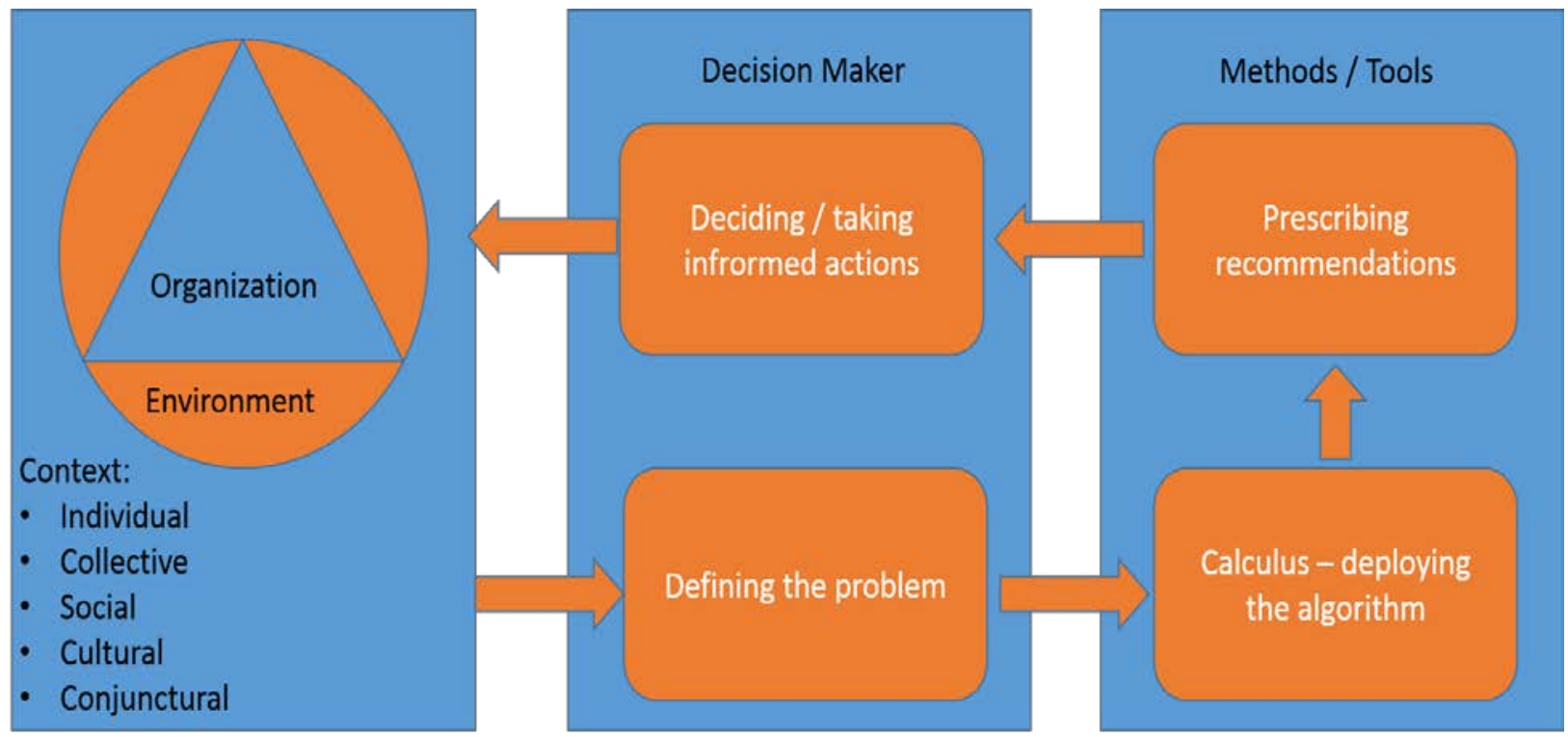

Figure 1 The methodology of the proposed multi-criteria decision support tool.

A multi-criteria decision support tool is what I propose [3] as a solution to go beyond these limits. The tool is based on a methodology that follows a two-step approach. The first step consists in „outlining and structuring the problem”. To do so, it is necessary to identify and explicit the stakes, the constraints, the actors and stakeholders concerned or affected by the SD problematic and then to choose the adequate method according to the level and to the nature of information and knowledge. The second step is the "implementation of a method". This step consists in restructuring the available information according to the method to be used and analyzing the results of the method in order to provide the adequate recommendation to the decision-maker. These two steps are described in figure 1.

\section{General principles of multi-criteria decision support methods}

The great majority of support systems tend to structure the decisional aid process into three principal phases: formulation of the problem, exploitation of the algorithm, and recommendations. Formulating a decision-making problem consists in finding an adequate model for the decision-making process. In a context where reality is represented by a multi-criteria form, this first phase consists of [1]:

- $\quad$ The identification of the actors, their value systems and the different significant points that affect the decision making process which can vary in time.

- $\quad$ Defining the actions that are elements of decision-making.

- $\quad$ Identifying decision making situations or alternatives. 
- $\quad$ Defining a set of criteria or a set of indicators and modeling the consequences of actions and drawing up criteria in order to compare the different actions with each other.

This phase is the most delicate one because the conclusions reached and the recommendations provided depend on the way in which the SD principle is considered. The second phase is more mathematical.

\section{The need of an integrated sustainability indicator}

The impact of industry on the environment and on the society can be determined in the "triple bottom line," which covers the three aspects of sustainability: economic performance, social responsibility and the environmental impact. As presented in the previous chapters of this research, many companies are addressing sustainable development and have different approaches in doing so. However, the achievement of these objectives needs not only a re-think of practices in industry, but also the instruments to monitor and measure the achievements that have been made in the transition process towards sustainability.

Until recent, companies have been using just classical, standard financial indicators to assess their business effectiveness, but considering the increased pressure and demand for sustainable practices, sustainability reports have become a new trend in the corporate reporting [4].

The sustainable organization needs to take into account several aspects that have been synthetized in performance indicators [5]. These indicators not only measure the economic performance, as they used to do until recently, but also assess social responsibility and environmental performance. They are known as sustainability indicators and translate sustainability issues into quantifiable measures with the ultimate goal to address key sustainability concerns [6] and to provide information on how the company contributes to sustainable development [7].

Dozens of indicators have been proposed for various aspects of the three components of sustainability, but integrating them into more comprehensive indexes has been a challenge and involved high mathematical skills, thus reducing their usage. Krajnc and Glavič [8] present the efforts that have been done in the development of composite indicators needed especially for comparison of economic, social and environmental and/or sustainable progress of nations, mainly in a quantitative mean. They summarize the indicators that have been applied in the mentioned fields, as follows:

- Environment: pilot environmental performance index [9], index of environmental friendliness [10], eco-indicator 99 [11];

- $\quad$ Economy: internal market index [12], composite leading indicators [13], index of sustainable and economic welfare [14];

- $\quad$ Society: human development index [15], overall health system attainment [16]; and

- Sustainability: Dow Jones sustainability index [17], index of balanced sustainable development [18].

Considering the above presented, it is essential to find a general sustainability index that should integrate the indicators presented in the model of the sustainable organization [19] and the others that have not been included into the graphic model due to space considerations. The Global Sustainability Index (GSI) aims to be a useful integrating instrument for measuring sustainability achievements of the company needed for decision-making and for raising the sustainability reporting to a higher level of consistency.

Thus, it is clear that it is essential for any company to have integrated information on sustainable development for the decision-making process, as it is very complicated to rely on too many indicators.

\section{Calculation of the Global Sustainability Index (GSI)}

The Global Sustainability Index (GSI) is the indicator that combines all the indicators presented in the model of the sustainable organization, that has been described elsewhere [19]. The triple approach indicates that the GSI should be calculated by grouping the three sub-indexes: the internal approach index, the external approach index and the operational approach index. Given the fact that these three approaches are the pillars of the sustainable organization, they should have all equal weights, but for the sake of flexibility to the needs and views of the decision maker, their weights should be determined using the method presented in the previous paragraph. The conceptual model of the eco-business-intelligence tool, which organizes data into relevant information for the transition towards sustainability, based on the sets of indicators that have been already described, is presented in figure 2 


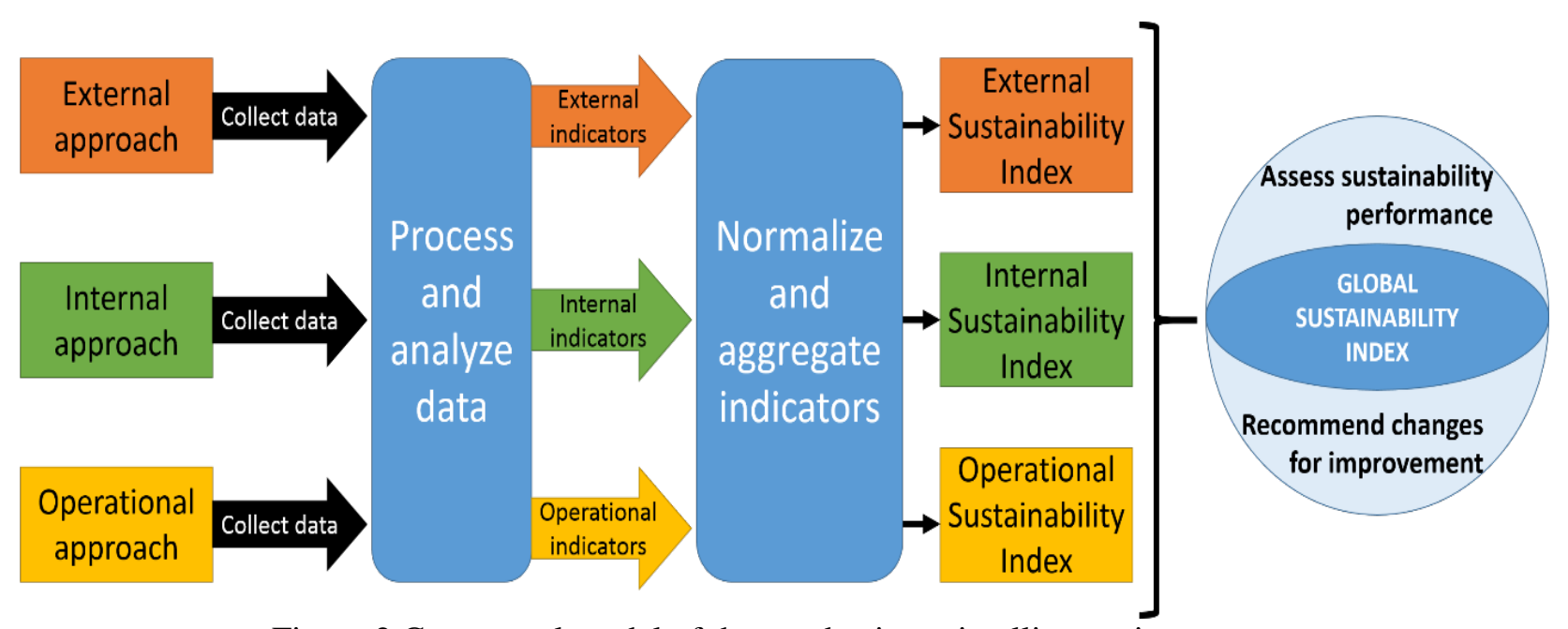

Figure 2 Conceptual model of the eco-business-intelligence instrument

Thus the Global Sustainability Index should be calculated using equation (1)

$$
\begin{array}{r}
G S I=\sum_{i=1}^{3} w_{i} \cdot T a I_{i} \\
\sum_{i=1}^{3} w_{i}=1, \quad w_{i} \geq 0 .
\end{array}
$$

Where GSI is the global sustainability index, TaIi represent the sub-indexes of the Triple approach = internal approach index; external approach index and operational approach index, while wi represent the weights of each of the three sub-indexes, calculated with the adapted FRISCO method, presented in [2].

The operational approach index, as indicated in the model of the sustainable organization [19] is calculated by grouping the sub-sub-indexes for each group of sustainability indicators: social, environmental and economic indicators. The aggregation formula is presented in equation (2)

$$
\begin{aligned}
& \operatorname{TaI}_{\text {op }}=\sum_{i=1}^{3} w_{i} \cdot I g_{i} \\
& \sum_{i=1}^{3} w_{i}=1, \quad w_{i} \geq 0 .
\end{aligned}
$$

Where TaIop is the sub-index for the operational approach, Igi represents the sub-sub-index for a group of indicators $\mathrm{i}$ (economic, $\mathrm{i}=1$; environmental, $\mathrm{i}=2$; social, $\mathrm{i}=3$ ) and wi is the weight of each subsub-index, calculated as well with the method described in [2].

\section{Conclusions}

The proposed mathematic algorithm for aggregating more sustainability indexes can be applied in the companies that want to assess their efforts in the transition towards sustainability and the GSI can be a useful measure of the current sustainability performance.

This paper highlights the need of decision makers to have a global sustainability index, to ease their decision, as it is very complicated to consider a very big number of sustainability indicators, with different measuring units. As the need for transforming in sustainable organization becomes more obvious, sustainability reporting is becoming more important and offers a broader view to those whose business is to assess the current sustainability health of companies and influence future action.

This paper not only offers the mathematical grounds for integrating the sustainability indicators into a general sustainability index, but also provides mathematical support for decision making when considering the implementation of measures for achieving the sustainability objectives of the organization.

There is rarely an optimal solution in SD but most frequently a need to build compromises between conflicting aspects such as economic, social and environmental ones and different expectations of stakeholders. Moreover, information is rarely available and precise. The combinative algorithm presented aims to help decision makers to cope with these difficulties. Implementing the proposed 
algorithm for a multi-criteria decision support system for a sustainable organization should be made through incremental steps, as shown, and should be a process of continual improvement in environmental, economic and social performance.

The proposed algorithm offers the opportunity to avoid monetization of the different dimensions of sustainability. These dimensions are not substitutable for one another and all have a role to play. Multicriteria decision support is a branch of decision theory where actions or alternatives are chosen considering several points of view or criteria, assuming that the decision maker has all the information at his disposal concerning the alternatives, i.e., they are fully described by a vector of attributes which is supposed to be known without uncertainty.

According to Merad et al [1], two main features of this kind of problem make it difficult to solve. The first one is that attributes describing alternatives are heterogeneous, i.e., they represent different physical (or economical, subjective, etc.) entities like price, size, colour, weight, etc. and may be numerical or not. Hence a first difficulty is to make them commensurable in some sense. The second feature is that points of view or criteria are more or less important to make a decision, and most often they are conflicting or interacting in some way, so that it is not obvious how to combine them for reaching a final overall opinion.

Due to organizational cultures of companies and natural human resistance to change, a series of barriers occur in the process of transition towards the sustainable organization. Barriers such as lack of awareness, lack of information, difficulties in understanding and operating mathematical algorithms could be overcome with an on-line version of the proposed algorithm that is subject for further research

\section{Acknowledgements}

This work was supported by the strategic grant POSDRU/159/1.5/S/133255, Project ID 133255 (2014), co-financed by the European Social Fund within the Sectorial Operational Program Human Resources Development 2007 - 2013.

\section{References}

[1]. Merad, M., Dechy, N., Serir, L., Grabisch, M., \& Marcel, F. (2013). Using a multi-criteria decision aid methodology to implement sustainable development principles within an organization. European Journal of Operational Research, 224(3), 603-613.

[2]. Grecu, V. and Denes, C., (2012a) A Decision Support System for the Transition Towards the Sustainable University, Proceedings of the International Conference on Engineering \& Business Education, Innovation and Entrepreneurship, Sibiu, Romania, 18 - 21 October, 2012, pp319-324

[3]. Grecu, V. (2014a), A multi-criteria decision support algorithm for solving sustainability problems within organization, Proceedings of the Joint International Conference of Doctoral and PostDoctoral Researchers, Craiova, 12-13 September 2014, pp 384-394

[4]. GRI-Global Reporting Initiative. (2002), Sustainability Reporting Guidelines 2002 on Economic, Environmental and Social Performance. Global Reporting Initiative, Boston, USA. Available at: http://www.globalreporting.org, 2002.

[5]. Grecu, V. and Nate, S., (2014), Managing sustainability with eco-business intelligence instruments, Management of Sustainable Development Sibiu, Romania, Volume 6, No.1, June 2014, pp.25-30, DOI 10.2478/msd-2014-0003

[6]. Azapagic A. (2004), Developing a framework for sustainable development indicators for the mining and minerals industry. J Cleaner Prod 2004; 12:639-62.

[7]. Azapagic, A. and Perdan, S., (2000), Indicators of sustainable development for industry: a general framework, Trans IChemE, Part B, Proc Safe Env Prot, volume 78, issue 4, pp243-261

[8]. Krajnc, D., Glavič, P. (2005). A model for integrated assessment of sustainable development. Resources, Conservation and Recycling, 43(2), 189-208.

[9]. WEF - World Economic Forum. (2002), An Initiative of the Global Leaders of Tomorrow Environment Task Force. Annual Meeting 2002. Pilot Environmental Performance Index. Available at: http://www.ciesin.columbia.edu/indicators/ESI/EPI2002 11FEB02.pdf, 2002.

[10]. Statistics Finland (2003), Index of Environmental Friendliness. Available at: http://www.stat.fi/tk/yr/ye22 en.html, 2003

[11]. Pr'e Consultants (2001), The Eco-indicator 99 - a damage oriented method for life cycle impact assessment. Methodology Report. Available at: http://www.pre.nl/, 2001. 
[12]. JRC - Joint Research Center (2002), Internal Market Index 2002: Technical Details of the Methodology. Institute for the Protection and Security of the Citizen, Technological and Economic Risk Management. Applied Statistics Group. Available at: http://www.jrc.cec.eu.int/, 2002.

[13]. OECD - Organization for Economic Co-operation and Development (2002), An Update of the OECD Composite Leading Indicators. Short-term Economic Statistics Division, Statistics Directorate/OECD. Available at: http://www.oecd.org, 2002.

[14]. Daly H, Cobb J. (1989), For the Common Good: Redirecting the Economy Towards Community, the Environment, and a Sustainable Future. Boston, MA, USA: Beacon Press; 1989

[15]. UNDP - United Nations Development Programme (1990-2003) Human Development Report. New York: Oxford University Press. Available at: http://hdr.undp.org/, various years, 1990-2003.

[16]. Murray CJL, Lauer J, Tandon A, Frenk J. (2001), Overall health system achievement for 191 countries. Global Programme on Evidence for Health Policy Discussion Paper Series: No. 28.World Health Organization (WHO). Available at: http://www3.who.int/whosis/discussion papers/pdf/paper28.pdf, 2001.

[17]. DJSI-Dow Jones Sustainability Indexes. (2014) Dow Jones Sustainability World Indexes Guide, Available at: http://www.sustainability-index.com

[18]. Seljak J. (2001) Sustainable Development Indicators, Ljubljana, Slovenia: Institute of Macroeconomic Analysis and Development (IMAD), 2001

[19]. Grecu, V. (2015), Managing Sustainability in Organizations with EcoBusinessIntelligence, LAP-LAMBERT Academic Publishing, Saarbrücken, Germany, ISBN 978-3-65976447-9, 